\title{
Contracampo
}

\section{Pacto de Visibilidade: Mídia, Celebridades e Humilhação}

\section{Pact of Visibility: Media, Celebrities and Humiliation}

João Freire Filho

joaofreirefilho@gmail.com

Doutor em Literatura Brasileira pela Pontifícia Universidade Católica-Rio. Professor associado da Escola de Comunicação da

Universidade Federal do Rio de Janeiro - UFRJ (Brasil). Bolsista de produtividade em pesquisa do CNPq - Nível 1D. Autor e editor de diversos livros, dentre eles: Reinvenções da resistência juvenil: os estudos culturais e as micropolíticas do cotidiano

(Mauad, 2007) e A TV em transição: tendências de programação no Brasil e no mundo (Sulina, 2009).

Lígia Lana

ligialana@gmail.com

Doutora em Comunicação Social pela Universidade Federal de Minas Gerais. Bolsista de Pós-doutorado Jr. (CNPq) na Escola de Comunicação da Universidade Federal do Rio de Janeiro (Brasil). Autora dos livros Gisele Bündchen e Luciana Gimenez: estudo comparativo das trajetórias de duas celebridades brasileiras (Novas Edições Acadêmicas, 2014) e Para além do sensacionalismo: uma análise do telejornal Brasil Urgente (E-papers, 2009). (PPGCOM/UFRGS).

\section{PPGCOM}

Ao citar este artigo, utilize a seguinte referência bibliográfica

FREIRE FILHO, João; LANA, Lígia. Pacto de Visibilidade: Mídia, Celebridades e Humilhação. In: Revista Contracampo, v. 30, n. 2, ed. agostonovembro ano 2014. Niterói: Contracampo, 2014. Págs: 4-23.

\section{Edição $30_{12014}$}

\section{Ensaio temático "Tabloidização na mídia"}

Contracampo

Niterói (RJ), v. 30, n. 2, ago-nov./2014

www.uff.br/contracampo

A Revista Contracampo é uma revista eletrônica do Programa de PósGraduação em Comunicação da Universidade Federal Fluminense e tem como objetivo contribuir para a reflexão crítica em torno do campo midiático, atuando como espaço de circulação da pesquisa e do pensamento acadêmico 


\section{Resumo}

Este artigo emprega os conceitos de celebridade e de humilhação consentida para analisar a projeção midiática de Geisy Arruda, hostilizada por colegas da Universidade Bandeirante de São Paulo (Uniban), em 2009. Após a ampla divulgação das imagens do vexame público, Geisy foi tratada como inquestionável vítima de preconceito. Com o fim da repercussão do episódio, a estudante adotou diversas estratégias para manter-se em evidência, concordando, muitas vezes, em ser depreciada ou ridicularizada por programas jornalísticos e humorísticos. Argumentamos que o caso em questão ilustra, perfeitamente, o pacto de visibilidade firmado entre candidatos à fama e setores da mídia crescentemente dispostos a converter a exibição da intimidade e o rebaixamento moral em fontes de entretenimento.

Palavras-chave: Celebridade; Visibilidade; Mídia; Humilhação; Geisy Arruda.

\section{Abstract}

This article examines the concepts of celebrity and consensual humiliation in order to analyze the mass media advent of Geisy Arruda, harassed by colleagues of University Bandeirante of São Paulo (Uniban) in 2009. After the widespread dissemination of images of public embarrassment, Geisy was treated as an unquestionable victim of prejudice. When the repercussion in media ended, the student has begun developing several strategies to keep in evidence, agreeing often in be ridiculed by journalistic and comedy TV shows. We argue that the case illustrated perfectly the pact of visibility signed between candidates for fame and media industry increasingly willing to convert the display of intimacy and moral degradation in entertainment.

Keywords: Visibility; Media; Humiliation; Geisy Arruda. 
$\mathrm{E}$ m 22 de outubro de 2009, Geisy Arruda - estudante do curso noturno de turismo da Universidade Bandeirante, em São Bernardo do Campo - foi à aula com um minivestido cor-de-rosa. Cerca de 700 alunos hostilizaram a colega, por causa do seu vestuário. Reunidos nos corredores da universidade, bradaram, em coro, "puta! puta! puta!”, chegando a intimidar Geisy com ameaças de estupro. Assustada, a aluna se escondeu em uma sala de aula. A polícia teve que escoltá-la até a saída da instituição de ensino. Geisy foi embora chorando; trajava, então, um jaleco branco. A perseguição gravada por celulares dos próprios alunos — foi divulgada, no dia seguinte, no YouTube. Uma semana depois, o caso repercutia, fortemente, no Brasil e no exterior.

O blog Boteco Sujo (atualmente desativado) foi o primeiro a exibir o vídeo, que se tornou um "viral" da internet. As imagens — com cerca de 30 segundos de duração - mostravam quatro policiais militares conduzindo uma mulher por um corredor, onde alunos vociferavam. O vídeo obteve, em uma semana, quase 20 mil acessos. ${ }^{1}$ Temendo a reverberação do episódio, a Universidade Bandeirante conseguiu a retirada da filmagem do YouTube, após alguns dias de circulação. ${ }^{2}$

A ação de censura não impediu, entretanto, a proliferação das imagens da “agressão à aluna da Uniban" nem a intensa veiculação de notícias a respeito do acontecimento, notadamente no período entre 28 de outubro e 15 de novembro de 2009.

\footnotetext{
1 Baccin (2012) mostrou que as postagens no Twitter e em blogs foram fundamentais para a elevação dos acessos ao vídeo, desde sua propagação inicial no Boteco Sujo.

2 A assessoria do Google no Brasil esclareceu que vídeos são retirados do YouTube caso apresentem "conteúdo impróprio e criminoso", denunciado por usuários. UNIVERSIDADE tenta apagar vídeo sobre aluna com roupa curta. Gl, 29 out. 2009. Disponível em: http://g1.globo.com/Noticias/SaoPaulo/0,,MUL1360027-5605,00UNIVERSIDADE+TENTA+APAGAR+VIDEO+SOBRE+ALUNA+COM+ROUPA+CURTA.html. Acesso em 30 jun. 2014.
} 
O caráter inusitado da situação (uma espécie de fait divers), a popularização espontânea das imagens e a tentativa da universidade de abafar o evento foram os primeiros tópicos abordados pela imprensa e por programas de televisão. Quais seriam, exatamente, as causas do ataque contra a estudante, naquela noite de quinta-feira? Apenas o uso inapropriado do vestido curto? Ou teria havido alguma outra motivação? E as consequências do caso? Qual a responsabilidade da universidade? Os códigos da moda ajudariam a explicar o ocorrido? Quem era, afinal, Geisy Arruda, a "loira da Uniban", e como ela se sentia naquele momento?

Em 30 de outubro, o Jornal Hoje (TV Globo) exibiu as imagens do evento, que "causou uma grande polêmica" depois de ser divulgado na internet, chamando a atenção de especialistas. ${ }^{3} \mathrm{O}$ educador e filósofo Mário Sérgio Cortela, entrevistado na matéria, afirmou que a jovem tem o direito de usar qualquer roupa, "desde que não ultrapasse aquilo que é a norma coletiva”. Para Cortella, endossado pelos apresentadores Sandra Annenberg e Evaristo Costa, a agressão e a violência dos colegas não seriam compatíveis com um "lugar que se chama universidade, onde se acolhe tudo que é diverso." Naquele mesmo dia, Geisy Arruda declarou à Rede Record que a perseguição teria começado com uma "brincadeira sadia" entre colegas de sala; porém, "conforme foi passando o tempo, acabou virando uma rebelião entre os alunos". Os insultos dos colegas e a zombaria de professores e de funcionários fizeram com que ela se sentisse como uma "criminosa". ${ }^{4}$ Em $1^{\circ}$ de novembro, a estudante apareceu novamente na televisão, desta vez no programa Fantástico, da Rede Globo, expondo argumentos semelhantes e cobrando a apuração das responsabilidades pela humilhação sofrida. ${ }^{5}$

O caso também se tornou pauta de reportagens sérias e de artigos opinativos na imprensa. Em $O$ Estado de S. Paulo, a hostilidade contra a estudante começou a ser noticiada em 31 de outubro, quando o jornal registrou outros casos de agressão na

3 JORNAL Hoje. Um assunto que provocou muita polêmica. TV Globo, Rio de Janeiro, 30 out. 2009. Disponível em: https:/www.youtube.com/watch?v=yaJ3eP_62AY. Acesso em 30 jun. 2014.

4 HOJE em dia. Jovem hostilizada em faculdade quer punição por insultos. TV Record, São Paulo, 30 out. 2009. Disponível em: http://noticias.r7.com/educacao/noticias/jovem-hostilizada-em-faculdade-querpunicao-por-insultos-20091030.html. Acesso em 30 jun. 2014.

5 NÃO recebi proteção nem segurança, diz estudante xingada por usar vestido curto. $G 1,1^{\circ}$ nov. 2009. Disponível em: http://g1.globo.com/Noticias/SaoPaulo/0,MUL1362978-5605,00-NAO+RECEBI+ PROTECAO+NEM+SEGURANCA+DIZ+ESTUDANTE+XINGADA+POR+USAR+VESTIDO+CU.ht ml. Acesso em 30 jun. 2014. 
mesma universidade e novas ameaças dos alunos à Geisy Arruda. No dia seguinte, em sua edição dominical, o jornal trouxe, no caderno Aliás, o artigo "O urro ancestral da universidade injuriada", assinado pela antropóloga Débora Diniz. O texto destacava o absurdo da violência dos estudantes, o "fascínio" do espetáculo gravado por câmeras de celulares e a desigualdade de gênero. A partir de 4 de novembro, a Folha de S. Paulo passou a cobrir o "Caso Uniban", informando que Geisy havia adiado a sua volta às aulas. Na internet, o assunto continuou em alta: portais como Terra, Uol e $I G$, postagens no Twitter $^{6}{ }^{6}$ comunidades no Orkut $^{7}{ }^{7}$ blogs de perfis editoriais distintos como o Escreva Lola Escreva ${ }^{8}$ e Chic Gloria Kalil ${ }^{9}$ divulgavam, cotidianamente, informações e opiniões sobre o caso.

Em 8 de novembro de 2009, surgiu a notícia de que a Universidade Bandeirante determinara a expulsão de Geisy Arruda. A decisão, tomada após uma sindicância interna, foi anunciada em um informe publicitário, veiculado na edição de domingo dos principais jornais brasileiros. No texto, intitulado "A educação se faz com atitude e não com complacência”, a universidade alegou que Geisy Arruda havia desrespeitado a "dignidade acadêmica" e a "moralidade". ${ }^{10}$ De acordo com a universidade, a estudante teria prestado depoimento na companhia de dois advogados e da estagiária de uma emissora de TV, expressando um "comportamento instável", oscilando entre a euforia e o desinteresse pelo caso. A universidade, por fim, convidou a comunidade acadêmica para um ciclo de debates sobre cidadania, porque a mídia não teria sido capaz, "uma vez mais", de realizar um debate público "sério e equilibrado".

6 As postagens traziam a hashtag \#UNItaleBAN.

7 Tais como “Apoiadores da Loira da Uniban", “Odiamos Geisy Arruda” e "Geisy Arruda faz programa”.

8 A postagem principal foi "A turba enraivecida da Uniban", onde estão citados os outros dois artigos, "Caso Uniban: tudo culpa dos gays e das mulheres" e "A desgraça da dicotomia: pare o pedestal que eu quero descer", publicados entre os dias 29 de outubro e 2 de novembro.

9 Postagem intitulada "É proibido proibir."

10 UNIBAN anuncia expulsão de aluna que usou vestido curto. $R 7,7$ nov. 2009. Disponível em: http://noticias.r7.com/educacao/noticias/uniban-anuncia-expulsao-de-aluna-que-usou-vestido-curto20091107.html. Acesso em 30 jun. 2014. 
Depois da expulsão da universidade, o caso Geisy Arruda passou a ser divulgado no exterior. Os jornais The New York Times, Washington Post, The Guardian, El País, Clarín, China Daily e as agências de notícias Associated Press e Reuters veicularam matérias sobre o evento. "A maior parte das reportagens reflete a surpresa dos estrangeiros ao constatar a repercussão em torno de um vestido curto no Brasil, país cuja imagem está intimamente ligada ao carnaval e às praias, onde as mulheres usam biquínis pequenos", sintetizou a $B B C$ Brasil. ${ }^{11}$ Apesar de a universidade ter revogado a expulsão da estudante no dia seguinte, o acontecimento já se consolidara como tema de discussão mundial. No Google Trends, a busca por "Geisy Arruda" foi registrada nos Estados Unidos, no Canadá, no México, na Inglaterra, em Portugal, na Espanha, na Alemanha e no Japão. Em 12 de novembro, o colunista Ancelmo Gois registrou, com perplexidade, que o site da $\mathrm{CNN}$ informara os quatro assuntos mais acessados por internautas do mundo todo, no dia anterior. O primeiro era a execução do atirador John Muhammad; o segundo, Geisy Arruda, “a estudante brasileira do microvestido que a Uniban quis expulsar." 12

A divulgação internacional do evento suscitou a publicação de mais conteúdo no Brasil. Geisy Arruda continuou concedendo entrevistas à televisão aberta, como para a apresentadora Sandra Annenberg, no Jornal Hoje, em 9 de novembro. ${ }^{13}$ Os portais brasileiros (Uol, G1, Terra) passaram a noticiar a repercussão internacional do assunto, estimulando os internautas a deixarem suas opiniões nas caixas de comentários; os textos sobre o caso ocuparam, por alguns dias, as listas dos "mais lidos" e dos "mais comentados". O Estado de S. Paulo constatou que a "expulsão de Geisy transformou a Uniban em alvo na internet", citando, com espanto, a unanimidade das críticas contra a universidade, tecidas por cronistas de orientações ideológicas discrepantes, de Luiz

11 IMPRENSA estrangeira mostra surpresa com caso de aluna hostilizada. BBC Brasil, 10 nov. 2009. Disponível em: http://www.bbc.co.uk/portuguese/noticias/2009/11/091110 unibanimprensa.shtml. Acesso em 30 jun. 2014.

12 GOIS, Ancelmo. Sucesso da minissaia. O Globo, Rio de Janeiro, 12 nov. 2009. Disponível em: http://oglobo.globo.com/rio/ancelmo/posts/2009/11/12/a-coluna-de-hoje-240350.asp. Acesso em 30 jun. 2014.

13 JORNAL Hoje. Aluna Geisy Arruda fala sobre expulsão da Uniban. TV Globo, Rio de Janeiro, 9 nov. 2009. Disponível em: https:/www.youtube.com/watch?v=d6Gd62q3DOQ. Acesso em 30 jun. 2014. 
Nassif a Reinaldo Azevedo. ${ }^{14} \mathrm{O}$ "caso Geisy Arruda" apareceu, ainda, nas capas dos jornais Folha de S. Paulo, O Estado de S. Paulo e O Globo.

De acordo com a cobertura midiática, após a expulsão de Geisy, os papéis de algoz e de vítima se tornaram nitidamente discerníveis: quando a hostilidade sofrida se converteu em condenação formal, a estudante passou a ser vista como a vítima no caso. Ganhando a solidariedade de diversos setores sociais, Geisy foi amparada, ao longo de duas semanas, pelo movimento feminista, pelo governo, por políticos, por intelectuais e por articulistas.

Segundo o Ministério Público, seria preciso averiguar o procedimento legal da expulsão, que não teria propiciado à Geisy Arruda o direito à ampla defesa; o Ministério da Educação cobrou explicações da universidade. Para o senador Eduardo Suplicy, a questão deveria estimular um debate sobre a educação no Brasil. A União Nacional dos Estudantes divulgou uma nota pública lamentando o "episódio de violência sexista" que acabara em "mais uma demonstração de machismo". ${ }^{15}$

Em 9 de novembro, uma manifestação na porta da universidade, em São Bernardo, contou com a presença da apresentadora Sabrina Sato, trajando um vestido cor-de-rosa. O slogan do protesto era "Basta de violência! O machismo mata!". Nem todos os estudantes presentes concordaram com a iniciativa, justificando que Geisy Arruda havia "queimado o filme da faculdade". ${ }^{16}$ Os alunos da Universidade de Brasília (UnB) se solidarizaram com Geisy Arruda, realizando uma manifestação em que alguns estudantes ficaram despidos.

Geisy Arruda foi hostilizada por infringir regras de quadros de conduta que orientam as interações sociais. O uso do minivestido, com insinuação sensual, não foi tolerado por seus colegas, porque acontecera em um ambiente específico, a

14 EXPULSÃO de Geisy transforma Uniban em alvo na internet. O Estado de S. Paulo, São Paulo, 9 nov. 2009. Disponível em: http://www.estadao.com.br/noticias/vidae,expulsao-de-geisy-transformauniban-em-alvo-na-internet,463508,0.htm. Acesso em 06 jun. 2013.

15 ALMEIDA, Lígia Martins. A culpada é a vítima. Observatório da Imprensa, 8 nov. 2009. Disponível em: http://www.observatoriodaimprensa.com.br/news/imprimir/17284>. Acesso em 06 jun. 2013.

16 FREITAS, Hermano. Protesto a favor de aluna xingada é vaiado por alunos da Uniban. Terra, 9 nov. 2009. Disponível em: http://noticias.terra.com.br/brasil/cidades/protesto-a-favor-de-aluna-xingada-evaiado-por-alunos-da-uniban,679168f40d94b310VgnCLD200000bbcceb0aRCRD.html. Acesso em 30 jun. 2014. 
universidade, instituição que presumidamente demandaria outro tipo de postura. ${ }^{17}$ Caso Geisy Arruda estivesse em uma boate - o que, como ela declarou, aconteceria naquela noite, após as aulas - seria improvável que a agressão tivesse ocorrido.

Ao tratar do vestuário da estudante, alguns textos da cobertura midiática abordaram essa inadequação. A psicanalista Maria Rita Kehl ponderou que Geisy havia sido "sem noção", por ter usado roupas impróprias à universidade. O caso não traria "convenções exatamente morais", mas alertaria para "convenções de comportamento" que "ajudam a clarear o que se espera das pessoas em determinados ambientes." 18 De maneira análoga, a consultora de moda Glória Kalil, no programa Fantástico e em seu blog, comentou:

\begin{abstract}
Por isso, vivo alertando sobre os riscos de não saber fazer a leitura correta do significado das roupas e sair por aí mandando sinais errados que vão ser mal interpretados. A jovem foi ingênua de achar que poderia ignorar os códigos da moda, que se baseiam em adequações: roupa certa para o lugar certo. Ela usou roupa de balada na hora errada e foi massacrada por isso. ${ }^{19}$
\end{abstract}

A condenação do vestido cor-de-rosa de Geisy Arruda demonstrou que a moda, como analisou Barthes (2005), constitui um sistema normativo, com regras, proibições e tolerâncias, que estabelecem significações históricas e culturais. Hoje em dia, uma mulher pode se vestir de maneira sensual para ir à boate ou ao shopping, sem ser hostilizada; pelo contrário, provavelmente ela será objeto de admiração. Em alguns quadros sociais, roupas justas, curtas e decotadas têm justamente o objetivo de conquistar a atenção das pessoas.

Geisy Arruda - ao relatar que, no início do episódio, envolveu-se em uma "brincadeira sadia" com seus colegas — assumiu que buscava ser notada, atitude incongruente com as atividades de um local de ensino (e mais condizente com uma boate). Seus colegas fizeram pior: a agressão moral, em massa, que quase se tornou uma

17 “Quadro social” visto aqui na perspectiva de Erving Goffman (2012).

18 KEHL, Maria Rita. Fascismo banal. Brasil de fato, 12 nov. 2009. Disponível em: http://www.brasildefato.com.br/node/3477. Acesso em 06 jun. 2013.

19 KALIL, Gloria. É proibido proibir. Chic Gloria Kalil, 2 nov. 2009. Disponível em: http://chic.ig.com.br/materias/517001-517500/517150/517150 1.html. Acesso em 06 jun. 2013. 
violência física, não seria tolerada nem mesmo em uma boate. Dessa maneira, uma das razões que fez com que o caso despertasse o interesse dos internautas, tornando-se, posteriormente, um acontecimento midiático, foi o espetacular registro de uma ruptura de quadros sociais: o ambiente noturno de uma universidade privada brasileira foi palco da quebra do frame escolar - que deveria primar pelo silêncio, respeito, concentração, fraternidade etc. A ruptura foi provocada, pois, tanto pela atitude insinuante de Geisy quanto pela violenta hostilidade dos colegas.

O jornalista Ruy Castro, na Folha de S. Paulo, apresentou as credenciais da Universidade Bandeirante (atualmente, integrante da Rede Anhanguera).

Belo ambiente. A Uniban, quarta maior universidade do Brasil em matrículas, está em $159^{\circ}$ lugar entre 175 avaliadas. Ou seja, é a $16^{\mathrm{a}}$ pior do país. Isso diz mais sobre o lamentável estado da educação entre nós do que cinco centímetros de perna de fora. ${ }^{20}$

A hostilidade contra Geisy Arruda revelou falhas e deficiências de estabelecimentos de ensino superior no país. As condutas de estudantes, professores, dirigentes e funcionários da Uniban foram questionadas, tornando visíveis problemas da educação brasileira. Apesar de celebrada como crítica aos "manuais de estilo jurássico" — “de Milão a São Bernardo do Campo, passando pelos Jardins, o último grito da moda é seguir a tendência Geisy: botar as pernocas de fora, bem na cara dos caretas" ${ }^{21}$ —, a roupa de Geisy Arruda não foi uma afronta ao conservadorismo. O minivestido cor-derosa teve significados muito diferentes da chocante minissaia que, na Swinging London dos anos 1960, se tornou emblema da liberação feminina. O comprimento da saia de Geisy serviu para revelar as condições do ambiente de ensino superior, que foi palco de um episódio de violência.

Geisy Arruda não foi humilhada por combater o conservadorismo e o desrespeito contra a mulher, mesmo tendo sofrido as suas consequências. No entanto, sua atitude, considerada "alienada" 22 e desprovida de propósito político, não justifica,

20 CASTRO, Ruy. Perna de fora. Folha de S. Paulo, 11 nov. 2009. Disponível em: http://www1.folha.uol.com.br/fsp/opiniao/fz1111200905.htm. Acesso em 30 jun. 2014.

21 LEITE NETO, Alcino. Minimania polêmica. Folha de S. Paulo, 13 nov. 2009. Disponível em: http://www1.folha.uol.com.br/fsp/ilustrad/fq1311200911.htm. Acesso em 30 jun. 2014.

22 KEHL, Maria Rita. Fascismo banal. Brasil de fato, 12 nov. 2009. Disponível em: http://www.brasildefato.com.br/node/3477. Acesso em 6 jun. 2013. 
de nenhuma maneira, a agressão que sofreu. A sombria violência do episódio foi diagnosticada, de maneira crítica, por diversos articulistas. A antropóloga Débora Diniz caracterizou bem os agressores. "Os delirantes não eram loucos internados em um manicômio à espera da medicação ou marujos recém-atracados em um cais após meses em alto-mar. Eram colegas de faculdade inconformados com um corpo insinuante coberto por um vestido rosa.",23

Depois da expulsão de Geisy Arruda, os articulistas buscaram explicar como a decisão "culpava a vítima”. Para o psicanalista Contardo Caligaris, "em caso de estupro, a gente sabe que a culpa é sempre da mulher; quem manda usar minivestido, hein? São todas putas, não é? Gostam de provocar e depois se queixam se os garotos as tratam como merecem. ${ }^{24}$ O jornalista Reinaldo Azevedo retomou o caso Ângela Diniz.

Um bando de rapazes que se comportaram como potenciais linchadores e estupradores e um bando de moças dispostas a coonestar o linchamento e o estupro. (...) Estamos de volta ao país de Ângela Diniz, que os mais jovens nem devem saber quem é. Vale uma pequena pesquisa sobre a "Pantera de Minas", assassinada por seu namorado, que foi absolvido (o julgamento depois foi revisto). Acusação: Ângela se comportava como "puta". Ficou famosa uma frase dita pelo advogado de Doca Street, o assassino: "Ela vivia mais na horizontal do que na vertical". Esmagava-se a reputação da vítima para poder inocentar o seu algoz. É o que faz o tal advogado da Uniban — que, Santo Deus!, também ministra um curso de Direito. ${ }^{25}$

A defesa midiática de Geisy Arruda, quase unânime, mostra que a agressão moral se situa em um quadro mais amplo de violência contra a mulher. A "sociologia do

23 DINIZ, Débora. O urro ancestral da faculdade injuriada. O Estado de S. Paulo, Aliás, 1 nov. 2009. Disponível em: http://alias.estadao.com.br/noticias/geral,o-urro-ancestral-da-faculdade-injuriada, 459621. Acesso em 30 jun. 2014.

24 CALIGARIS, Contardo. Impasse de um sonho moderno? Folha de S. Paulo, Ilustrada, 12 nov. 2009. Disponível em: http://www1.folha.uol.com.br/fsp/ilustrad/fq1211200927.htm. Acesso em 06 jun. 2013.

25 AZEVEDO, Reinaldo. Geisy é expulsa da Uniban. Barbárie fascistóide! Mulheres do Brasil, unam-se contra o "direito ao estupro". Blog do Reinaldo Azevedo, Revista Veja, 8 nov. 2009. Disponível em: http://veja.abril.com.br/blog/reinaldo/geral/geisy-expulsa-da-uniban-barbarie-fascistoide-mulheres-dobrasil-unam-se-contra-o- $\% \mathrm{E} 2 \% 80 \% 9$ Cdireito-ao-estupro $\% \mathrm{E} 2 \% 80 \% 9 \mathrm{D} /$. Acesso em 6 jun. 2013. 
vestuário" seria apenas um "recurso retórico para encobrir a real causa da violência — a opressão do corpo feminino." 26

Ao final da narrativa do caso, aproximadamente em 15 de novembro, o fait divers, onipresente em programas de televisão, portais da internet, blogs e colunas de jornais, transformou a estudante Geisy Arruda em uma celebridade. Além da exposição maciça, o apoio que recebeu de articulistas tão distintos (uma respeitada antropóloga, um psicanalista, um jornalista "conservador de direita" e outro "libertário de esquerda"...) concedeu-lhe visibilidade positiva. Quando surgiu na mídia, Geisy Arruda era uma vítima, que necessitava de reparação ao dano sofrido.

No final de 2009, os acontecimentos e os argumentos listados até aqui explicariam a fama repentina de Geisy Arruda, protagonista de um evento que dramatizara o preconceito e a violência contra a mulher e a estrutura precária de algumas universidades no país. Todavia, quando a repercussão midiática do episódio dava mostras de ter chegado ao fim, a jovem passou a desenvolver estratégias para permanecer em evidência. O debate moral em torno do "caso Geisy Arruda" foi, repentinamente, suplantado pela divulgação assídua de pseudoeventos estrelados pela "estudante polêmica". 27

Em 17 de janeiro de 2010, por exemplo, Geisy Arruda foi tema de uma reportagem no programa Fantástico, quando apresentou seu "novo visual". ${ }^{28} \mathrm{O}$ repórter narrou o segredo de toda aquela "transformação": "O que era barriga virou bumbum, o

26 DINIZ, Débora. O urro ancestral da faculdade injuriada. O Estado de S. Paulo, Aliás, 1 nov. 2009. Disponível em: http://alias.estadao.com.br/noticias/geral,o-urro-ancestral-da-faculdade-injuriada, 459621. Acesso em 30 jun. 2014.

27 O neologismo "pseudoevento" foi cunhado pelo historiador estadunidense Daniel Boorstin, nos anos 1960, para caracterizar a confecção de atividades, artefatos ou reputações (conferências de imprensa; press releases; debates presidenciais; celebridades; atrações turísticas; compilações), planejadas com a finalidade precípua de fisgar a atenção do público, em detrimento de outros critérios mais elevados de valor. Na "era dos pseudoeventos", as perguntas Isto é significativo? ou Isto é real? se tornavam menos relevantes do que a indagação Isto é noticiável?. Em tais circunstâncias, a liberdade de imprensa outrora preservada por seu interesse comunitário — se convertia, com penosa frequência, em simples anteparo retórico para os repórteres produzirem suas "mercadorias sintéticas" — ou seja, pseudoeventos que, graças à sua própria natureza pré-fabricada, eram mais "persuasivos", "dramáticos", "inteligíveis" e "reconfortantes" do que qualquer acontecimento espontâneo, como um encontro, uma conversa ou uma performance casual (BOORSTIN, 1992).

28 FANTÁSTICO. O novo visual de Geisy Arruda. TV Globo, Rio de Janeiro, 17 jan. 2010. Disponível em: https://www.youtube.com/watch?v=AoaLebeDA2Q. Acesso em 30 jun. 2014. 
que era gordura desagradável vira uma maravilha." Trajando um pequeno biquíni em uma cama de tratamento estético, Geisy Arruda revelou: "eu nem me reconheço."

Para manter sua presença na mídia, além de divulgar suas cirurgias plásticas, ${ }^{29}$ Geisy Arruda criou a marca de roupas "Rosa Divino", especializada em fabricar vestidos cor-de-rosa. Em abril de 2010, Geisy promoveu o lançamento da grife em um hotel de São Paulo, evento noticiado pela imprensa nacional. ${ }^{30}$ Em novembro de 2010, Geisy posou nua para a revista brasileira Sexy. A edição foi a mais vendida em cinco anos. O ensaio fotográfico fazia referência ao episódio da Uniban: Geisy usava, na capa da publicação masculina, um vestido cor-de-rosa e, em algumas fotografias, segurava caderno e caneta. Logo em seguida, Geisy foi contratada pela Rede Record. Ela participou da terceira edição do reality show A Fazenda, versão brasileira de The Farm (criado por Strix, Sony e Endemol). Depois, atuou na "Escolinha do Gugu", quadro do dominical Programa do Gugu, em que representava a personagem "dona Geisy", cujo bordão era "eu repito de ano, mas não repito o vestido.” Desde julho de 2013, Geisy Arruda não possui mais vínculo trabalhista com a emissora.

O fato parece não constituir um problema para a conservação de sua notoriedade. Ciente das regras da cultura tabloide, Geisy Arruda relata sua vida privada nas redes sociais da internet, promovendo a própria visibilidade, consentindo em apresentar-se como produto a ser explorado por publicações especializadas e outras vertentes da mídia. As imagens e as narrativas da sua intimidade se tornam notícias em sites de fofoca e ganham inúmeros acessos em portais de informação. Os temas

29 Como mostra George Vigarello (2006), a cirurgia estética surge nos anos 1930, em um contexto da busca pelo "corpo profundo", em que mulheres precisam descobrir sua personalidade e construir sua própria aparência. "Buscar essa verdade interior determinaria a atitude estética: criar um corpo que materializa a parte mais profunda de si, trabalhar nele para melhor trabalhar sobre si" (VIGARELLO, 2006, p.183). Mais importante, portanto, que a magreza do corpo é a sua moldagem através do trabalho sobre si, elaborado por vontade própria e orientado por uma individualidade singular. A cirurgia plástica dá a sensação do controle do próprio corpo - afinado, reduzido, moldado e reparado, o corpo desejável é resultado de uma transformação.

30 No desfile de apresentação da marca, as modelos eram familiares de Geisy Arruda - mãe, tias, sobrinhas e primas, entre elas, duas crianças. $\mathrm{Na}$ ocasião, ela declarou que seria mais fácil fazer roupas para "modelos lindas e magras", mas que seu público alvo era a mulher brasileira. "MINHA inspiração é a dona de casa", diz Geisy, em lançamento de sua grife. G1, 30 abr. 2010. Disponível em: http://g1.globo.com/sao-paulo/noticia/2010/04/minha-inspiracao-e-dona-de-casa-diz-geisy-emlancamento-de-sua-grife.html. Acesso em: 11 ago. 2014. 
divulgados são, amiúde, extremamente banais ("dia de sol na piscina", "ida ao teatro" e "penteado liso e longo"). Sem melindres, Geisy Arruda revela, também, particularidades da sua intimidade: no final de 2012, a cirurgia de redução dos pequenos lábios de sua vagina se tornou um trend topic mundial no Twitter — "Eu não tinha uma vagina, tinha uma couve flor", esclareceu mais tarde, em seu perfil. ${ }^{31}$ Em programas de televisão, como Superpop (Rede TV!) e Domingo Espetacular (Rede Record), e em diversos portais de notícias, Geisy forneceu novas justificativas para o procedimento cirúrgico: "Era uma coisa que me incomodava muito. Eu não conseguia usar biquínis. Meus lábios vaginais eram muito grandes e ficava com volume. Eu tinha vergonha durante as relações. Eu falava para o cara: 'Não olha!'. Era feio."32 Sob o olhar das câmeras, a vergonha que afirmava sentir em suas relações íntimas desapareceu, subitamente.

$\mathrm{Na}$ atualidade, o perfil de Geisy Arruda no Twitter possui cerca de 200 mil seguidores. Ela parece ser onipresente, de fato, na internet. No site Ego, do portal Globo.com, Geisy possui uma seção própria, em que são reunidos dados biográficos e as últimas notícias de suas aparições públicas, como a participação em campanhas publicitárias ou a presença em festas. Quase diariamente, Geisy posta fotografias nas redes sociais em que, normalmente, aparece com roupas justas, curtas e decotadas, semelhantes ao vestuário que provocou sua entrada no espaço midiático. $\mathrm{O}$ corpo em exibição é, muitas vezes, alvo de zombaria. No site de humor Desciclopédia, paródia do Wikipédia, o primeiro sinônimo para "Geisy Arruda" é "gordelícia de Diadema".

Geisy Vila Nova Arruda, vulgo Loirão, filha de José Roberto Arruda e irmã bastarda e loira da Preta Gil que sofre de vitiligo agudo, também conhecida como a loira do banheiro (masculino) da UniBan, é uma estudante que, por ser muito pobre e por não ter dinheiro para comprar tecido suficiente, foi obrigada a ir com um vestido fora dos padrões talUnibanicos pelos corredores da universidade e acabou hostilizada pelos seus coleguinhas afegãos e acabou sendo aclamada celebridade instantânea da vez pela mídia.

31 No Twitter, o perfil de Geisy Arruda é https://twitter.com/geisyarrudareal.

32 KRISS, Elba. Geisy Arruda fala sobre cirurgia íntima: "Era uma coisa que me incomodava". Portal $R 7,8$ nov. 2012. Disponível em: http://entretenimento.r7.com/famosos-e-tv/noticias/geisy-arruda-fala-sobre-cirurgia-intima-era-umacoisa-que-me-incomodava-20121108.html?question=0. Acesso 6 jun. 2013. 
Geisy é a famosa gordelícia, aquele tipo de sem noção gordinha que se considera e é considerada por alguns como mulher gostosa. ${ }^{33}$

Nos momentos subsequentes à sua aparição na mídia, Geisy Arruda não figura mais como vítima de um caso de humilhação e símbolo da luta por reconhecimento (já que as desigualdades identitárias entre os gêneros haviam sido enfocadas, inicialmente). A insistência em promover a própria imagem faz com que Geisy seja vista como uma mulher oportunista, interessada em tirar partido de um episódio deplorável. Em uma entrevista ao blogueiro Maurício Stycer, Geisy admitiu que criou uma personagem: "As pessoas me acham polêmica (...) e acho que criei um personagem, aquela mulher que causa. E eu não sou nada disso, mas é isso que eu vendo, é disso que eu sobrevivo. (...) Eu fui uma das periguetes que deu certo." 34

Geisy Arruda "deu certo" porque amealhou capital de visibilidade (HEINICH, 2012), ingressando para a constelação de indivíduos que possuem uma face visível a muitos, passível de contemplação e de reprodução técnica. Para firmar-se como celebridade - isto é, como representante de uma nova "elite do poder", surgida ao longo do século XX (MILLS, 1975) —, Geisy adota, sem constrangimentos, o lema falem mal, mas falem de mim, gerando rumores, notícias, publicidade.

Em 23 de fevereiro de 2014, Geisy Arruda participou do Poderoso Castiga, quadro de entrevistas do humorístico Pânico na Band. Apresentado por Eduardo Sterblitch, o Poderoso Castiga é uma paródia do formato talk show. Expressando-se por meio de sucessivos palavrões, o apresentador - que se autodenomina "um grandessíssimo filho da puta" - formula perguntas irônicas, faz críticas debochadas, constrangendo os entrevistados - geralmente, subcelebridades como Andressa Urach, Mr. Catra, Suzy Pianista e Théo Becker. Ao aceitar o convite para uma entrevista, Geisy Arruda sabia, de antemão, que enfrentaria perguntas desrespeitosas; como recompensa, acumularia mais um montante de capital de visibilidade. ${ }^{35}$

33 GEISY Arruda. Desciclopédia, 31 dez. 2013. Disponível em: http://desciclopedia.org/wiki/Geisy Arruda. Acesso 11 jun. 2014.

34 STYCER, Maurício. Geisy Arruda: criei um personagem. Blog do Maurício Stycer, 9 ago. 2012. Disponível em: http://mauriciostycer.blogosfera.uol.com.br/2012/08/09/geisy-arruda-criei-umpersonagem/. Acesso em 6 jun. 2013. 
"Você é pegadora?", "Dadeira? Você gosta de esfolar, assim... esfola mesmo, você dá uma esfolada?", "Você já transou dormindo? Dormiu transando?", "Você é loura de verdade... você pinta tudo?", "Você operou a sua xalalica?... Foi porque [es]tava feia, você usou muito?”, “Qual é a sua posição preferida? Gordinha, normalmente, gosta de usar a boca..." inquiriu o apresentador, em 12 minutos de conversa. ${ }^{36}$ Sempre com um sorriso no rosto, Geisy Arruda respondeu afirmativamente a todas as perguntas. A certa altura, confidenciou: "Gosto também de sexo selvagem". Foi a deixa para que o Poderoso indagasse: "Eu posso enfiar esta chave, aqui, inteira?", referindo-se a um objeto cenográfico. "Não, isto aí não entra", retrucou a entrevistada.

Ao longo do talk show, Geisy tomou várias doses de uma "bebida forte". "Eu quero que você beba, para eu pedir pra você mostrar o seio pra mim, para que eu vomite", comentou o Poderoso. Geisy gargalhou. A conversa passou a girar, então, em torno da atividade profissional da entrevistada.

Poderoso: - Por que diabo você resolveu virar artista, foi para ganhar dinheiro?

Geisy: - É, ganhar dinheiro fácil, sim.

Poderoso: - Não era mais fácil se prostituir?

Geisy: - Não, dá muito trabalho...

Interrogada, anteriormente, sobre o valor cobrado para fazer programas, Geisy permanecera em silêncio. Mas, quando o Poderoso insinuou, mais adiante, que gostaria de transar com ela, a entrevistada olhou para as câmeras, levantou a mão direita e esfregou o dedo indicador no polegar, reproduzindo o típico gesto de contagem de dinheiro. "Vem cá, se for pagando é mais fácil...", animou-se o apresentador. "Não, eu sou daquelas que dá de graça...”. Depois, de costas para a câmera, mostrou, supostamente, os seios para o Poderoso. Em seguida, ficou de quatro no palco, encenando a sua posição sexual favorita... "Encaixa aí para você ver que encaixa!...”.

lucrado, vendido, acumulado, transmitido e convertido - para a sobrevivência dos indivíduos a partir da avaliação mensurável daquilo que pode ser exposto. Analisando o conceito de capital simbólico, de Pierre Bourdieu, Heinich argumenta que o capital de visibilidade é regulado por normas econômicas particulares. Após a crescente disseminação de imagens no século XX, a definição das hierarquias sociais passa a ser afetada pelas variações do capital de visibilidade.

36 PÂNICO na Band. Poderoso Castiga entrevista Geisy Arruda. Band, São Paulo, 23 fev. 2014. Disponível em: https://www.youtube.com/watch?v=dw2ZOLJzYAQ. Acesso em 30 jun. 2014. 
"Se eu ficar pelado, você fica?" "Não, não, não dá, eu não sou tão bonita quanto as panicats...". Depois de chamá-la de "gorda enorme", o Poderoso aperta o seio de Geisy três vezes. "Eu queria bastante ir com você pra casa, pra te pegar durante umas duas horas, depois me arrepender pra caralho...”. Na última cena do programa, Geisy “chupa o mamilo" do apresentador.

Em 2009, quando foi insultada por colegas da sua universidade, Geisy Arruda manifestou indignação e buscou reparação para a humilhação sofrida. Na perspectiva do sujeito que se crê aviltado, a humilhação é um gesto ou um processo indevido de rebaixamento (humus, em latim, significa "terra", "solo", "chão"). Não é à toa, pois, que nos referimos aos humilhados, alternativamente, como espezinhados (comprimidos, esmagados com os pés) ou degradados (privados de graduação; rebaixados de posto ou de posição na hierarquia eclesiástica, militar ou social). A presumida depreciação da honra, do mérito ou da dignidade pode gerar condições e reações emocionais distintas: sobressaem, em alguns casos, o desalento, a consternação e, até mesmo, a diminuição do amor-próprio; em outros casos, vigoram o ressentimento, a raiva contida, o desejo de vingança, todo um complexo afetivo que o escritor James Baldwin denominou "a ira do desprezado" (BALDWIN, 1998, p. 121-122).

Acreditando-se vítima de significativa humilhação, Geisy procurou consertar as avarias em sua reputação, recorrendo à justiça e também à mídia, que generosamente lhe abriu as portas para externar as suas impressões sobre a condenação pública. No entanto, para forjar uma imagem ou uma persona continuamente interessante, a estudante humilhada e ofendida consentiu em participar, depois, de rituais midiáticos de degradação pública. No Poderoso Castiga, Geisy acolheu, sem protestar, uma série de observações desabonadoras sobre o seu físico e o seu caráter, além de tratar, com jovialidade, a sugestão de que era, de fato, uma "prostituta".

Resumindo, Geisy Arruda, empreendedora da própria imagem, abrira mão do respeito, em nome do espetáculo. Ambos os termos estão associados, etimologicamente, ao direcionamento do olhar e à conquista da atenção. A palavra respeito provém do verbo latino respicere, que significa "a ação de olhar para trás", "olhar atentamente"; respicio equivale a "olhar com consideração"; respectus, ao resultado do olhar cuidadoso. O prefixo re- anteposto a spectáre pode significar tanto o retorno do olhar quanto a intensificação da mirada, o prolongamento da atenção. 
De acordo com Esquirol (2008), o respeito corresponde a um "olhar ético", sustentado pelo vínculo entre atenção e pensamento moral - o que o diferenciaria do olhar insistente e intrometido dos bisbilhoteiros. O olhar atento, o "olhar ético" é aquele pautado pelo comedimento, dirigido com cautela e graduação de força: "Olhar atentamente não é cravar o olhar, e sim dirigir o olhar com cuidado, sem pressa e com flexibilidade suficiente, de maneira a poder desviá-lo quando a situação assim o exija" (ESQUIROL, 2008, p. 12-13).

O movimento do respeito consiste, portanto, num aproximar-se que guarda a justa distância, que preserva o espaço conveniente ao outro. É por isso que a violência representa a antítese do respeito, já que coincide exatamente com a supressão de toda distância, com um tipo de força física ou psicológica que incide sobre alguém:

A violação tem a mesma raiz que a violência. (...) A violência é a violação do outro, da pessoa do outro, em cada uma das suas dimensões: a violência sobre o corpo, sobre sua presença social, sobre seu espaço íntimo - sua intimidade —, sobre suas ideias ou suas crenças... (idem, p. 50).

O respeito, conclui Esquirol, é aquilo que nos protege da presunção excessiva de nossos conhecimentos e das veleidades de nossos desejos:

O mundo descoberto pela atenção não faz parte de minhas propriedades, nem de meu domínio, e, ao levá-lo realmente em conta, corrigimos nossos impulsos egoístas. Por isso, a verdadeira atenção é a porta de entrada à consideração do outro como tal, ao respeito (idem, p. 97).

Trata-se de uma forma de aproximação que demanda comprometimento efetivo, que jamais assume função meramente utilitária, de exploração da intimidade alheia (explorar deriva de explicitar, explicitare, "extrair; aproveitar até o fim; pôr a descoberto; tirar o que está dentro das coisas"); tampouco se deixa nortear, exclusivamente, por ideias feitas, dogmatismos, estereótipos, confortáveis esquemas prefixados de apropriação e controle. A chave do respeito consiste, ao contrário, numa abertura para a admiração genuína ante o que é peculiar no outro. Gesto bastante distinto do "espanto pré-fabricado através de estratégias comerciais e de espetáculos de massa" (ESQUIROL, 2008, p. 69).

Espetáculo advém do latim spetaculum, substantivo derivado, por sua vez, do mesmo verbo spectáre, "olhar, observar, contemplar". Desde a antiguidade, o vocábulo 
é usado para designar eventos, encenações e edificações que captam a atenção pela singularidade, beleza, engenhosidade, magnificência ou vibração - das sete maravilhas do mundo às performances dos gladiadores nas arenas romanas. A organização de um campo e de uma experiência visual fascinante gera, amiúde, desconfianças de natureza política ou moral. A teoria crítica do espetáculo tende a relacioná-lo com estratégias não coercitivas de poder e persuasão - tanto em regimes monárquicos pré-modernos quanto em formações estatais modernas e pós-modernas (CRARY, 2005). São denunciados, também, as comoções e os assombros preconcebidos com a finalidade de mesmerizar as audiências da indústria cultural. O problema do espetáculo, por este prisma, consiste em sua capacidade de minar a perspectiva crítica dos cidadãos. Já na defesa cotidiana da moralidade, qualifica-se de espetaculoso o indivíduo que monopoliza a atenção mediante uma apresentação pública inapropriada: cenas escandalosas, roupas espalhafatosas, gestos extravagantes, como os adotados por Geisy Arruda.

$\mathrm{Na}$ internet, comentários tecidos por pessoas comuns em portais de notícias denotam, com frequência, um desprezo por Geisy Arruda. Recentemente, a divulgação de um aborto espontâneo, causado devido a uma gravidez de risco, provocou um intenso debate. No site Ego, por exemplo, a notícia foi comentada de maneira mordaz pelos usuários: "Foi até bom ele ter ido! Menos um verme no mundo." ${ }^{37}$ Mesmo anunciando estar com o "coração despedaçado", Geisy não obteve a piedade dos comentaristas do Ego. "Se fosse do roberto justos, do neymar ou de algum milionário queria ver. burra ve se aprende a liçao e vá estudar ou fazer algo para que possa se sustentar sem se expor tanto ao ridiculo" [sic]. Além disso, a informação é tratada com descrédito.

eu cantei a pedra!!!! Ahahahaahahaha...estava tudo armado e pronto!!!! Essa gestação era FAKE desde o início!!!! Essa mulamba e seus asseclas fazem de tudo para continuar na mídia!!!! Inacreditável!!!!

Ainda que o Ego tenha publicado a reprodução de um exame de gravidez, os usuários continuaram desconfiando da notícia. "Qualquer um faz uma folha dessas no computador em casa e põe até o nome do Marquito como a 'grávida' em questão".

37 Todos os comentários foram postados em "Geisy Arruda revela que perdeu o bebê: 'Coração está despedaçado", publicados no site Ego em http://ego.globo.com/famosos/noticia/2014/05/geisy-arrudaperde-o-bebe-meu-coracao-esta-despedacado.html. Acesso em 14 jul. 2014. 
Em 2 de agosto de 2012, o programa Domingo Espetacular divulgou uma pesquisa de opinião que mostrava que o corpo de Geisy seria modelar para 15 mil mulheres brasileiras. Suas concorrentes eram Gisele Bündchen e Juliana Paes, o que sugere a preferência por seios fartos, quadris largos e coxas grossas. Nas imagens mostradas aos entrevistados, as cabeças das três foram suprimidas, aspecto lembrado por Geisy em sua conta no Twitter ("só ganhei a pesquisa porque cortaram a cabeça da mulherada...") e retomado na entrevista ao programa de TV ("mesmo que fosse a mesma foto, mas mostrando meu rosto, eu não teria recebido essa quantidade de votos"). ${ }^{38}$ Geisy Arruda sabe, portanto, que não possui uma imagem pública positiva, que o consumo de notícias a seu respeito está vinculado, frequentemente, à satisfação do desejo do público de sentir-se superior aos notáveis, ao prazer de escarnecer das conspícuas fragilidades físicas, culturais ou morais alheias.

Sem talentos, conquistas, qualidades ou "virtudes sólidas" (BOORSTIN, 1992) aparentes, oriunda de uma família de baixa renda, Geisy investiu na promoção de uma personagem que atrai pela estupidez hilária, pela sensualidade descarada e pelo anseio desmedido de celebridade - uma forma diferenciada de projeção na esfera pública: imediata; mundana; talvez transitória; desatrelada das instâncias tradicionais de consagração; dependente, essencialmente, do poder jornalístico de gerar publicidade e de produzir reconhecimento, ainda que à custa de abordagens desrespeitosas. Para gozar dos benefícios da celebridade — ser reconhecida e "viver da própria imagem", transcendendo a monotonia do trabalho e do cotidiano plebeu -, Geisy Arruda desnuda sua intimidade e expõe-se à humilhação pública. Subscreve um pacto de visibilidade em que se dispõe a atuar como uma forma degradada de "entretenimento humano" (GABLER, 1999) — fazendo graça ou servindo de piada em programas humorísticos; aceitando convites para posar sem roupa; submetendo-se a cirurgias plásticas; namorando pessoas famosas ou separando-se delas... - em troca da visibilidade midiática — tonificadora da autoestima e abastecedora da conta bancária.

38 DOMINGO Espetacular. Geisy Arruda tem o tipo físico mais desejado segundo pesquisa. TV Record, São Paulo, 2 ago. 2012. Disponível em: http://www.youtube.com/watch?v=orcfshkn9si. Acesso em 14 jul. 2014. 


\section{Referências bibliográficas}

BACCIN, Alciane. A construção do acontecimento jornalístico Geisy Arruda. Uniban: do vídeo no Youtube à biografia. São Leopoldo, RS. Dissertação de mestrado. Programa de Pósgraduação em Ciências da Comunicação da Universidade do Vale do Rio dos Sinos, 2012, 192 p.

BALDWIN, James. Stranger in the village. In: MORRISON, Toni (Ed.). James Baldwin: collected essays. Nova Iorque: Library of America, 1998, p. 117-29.

BARTHES, Roland. Inéditos, vol. 3. Imagem e Moda. São Paulo: Martins Fontes, 2005.

BOORSTIN, Daniel. The image: a guide to pseudo-events in America. Nova Iorque: Vintage Books, 1992.

CRARY, Jonathan. Spectacle. In: BENNETT, Tony et al. (Eds.). New keywords: a revised vocabulary of culture and society. Malden, MA: Blackwell Publishing, 2005, p. 335-336.

ESQUIROL, Joseph. O respeito ou o olhar atento: uma ética para a era da ciência e da tecnologia. Belo Horizonte: Autêntica, 2008.

GABLER, Neal. Vida, o filme: como o entretenimento conquistou a realidade. São Paulo: Companhia das Letras, 1999.

GOFFMAN, Erving. Os quadros da experiência social: uma perspectiva de análise. Petrópolis: Vozes, 2012.

HEINICH, Nathalie. De la visibilité: excellence et singularité en régime médiatique. Paris: Editions Gallimard, 2012.

LANA, Lígia. A vítima oportunista: a construção da celebridade Luciana Gimenez. Interseções (UERJ), v. 15, p. 446-462, 2013.

LANA, Lígia. A mulher bem-sucedida e a participação da internet na construção de celebridades femininas. XXXVI Congresso Brasileiro de Ciências da Comunicação (Intercom), v. único. p. 1-15, 2013.

MILLS, Charles Wright. As celebridades. In: A elite do poder. Rio de Janeiro: Zahar, 1975 , p. 88-115.

VIGARELLO, George. História da beleza. O corpo e a arte de se embelezar, do renascimento aos dias de hoje. Rio de Janeiro: Ediouro, 2006. 